\title{
Effects of Molecular Weight on the Melting and Crystallization of Poly(L-lactic acid) in a Mixture with Poly(ethylene oxide)
}

\author{
Chitoshi Nakafuku \\ Faculty of Education, Kochi University, Kochi 780, Japan
}

(Received October 30, 1995)

\begin{abstract}
The melting and crystallization behavior of poly(L-lactic acid) (PLLA) of different molecular weight $(M W=2000,66000$, and 152000) in the binary mixture with poly(ethylene oxide) (PEO) of the different molecular weight $(M W=3000,100000$, and 5000000) was studied by DSC, wide angle X-ray diffraction measurement and optical microscopy. Melting and crystallization process of PLLA depends on molecular weights of PLLA and PEO. Melting temperature ( $\left.T_{\mathrm{m}}\right)$ of the low molecular weight PLLA decreased drastically below the weight fraction of PLLA 0.2 . $T_{\mathrm{m}}$ of high molecular weight PLLA decreased with decreasing PLLA in the mixture with low molecular weight PEO, while drastic decrease did not occur in the mixture with high molecular weight PEO. Temperature change of the morphological features of PLLA in the binary mixture depends on the molecular weight of PLLA and weight fraction of PEO.
\end{abstract}

KEY WORDS Poly(L-lactic acid) / Poly(ethylene oxide) / Binary Mixture / Melting / Crystallization / Differential Scanning Calorimetry / X-Ray Diffractometry / Optical Microscopy /

In recent years, many papers were published on the melting and crystallization of poly(L-lactic acid) (PLLA). These include pure PLLA ${ }^{1}$ and PLLA in the mixture with other polymers. Migliaresi et al. performed a dynamic mechanical and calorimetric study on pure PLLA and reported the crystallization in heating for the quenched sample. ${ }^{2}$ Park et al. reported the phase separation of blends of PLLA and triblock copolymers of poly(ethylene oxide) (PEO)/poly(propylene oxide) (PPO)/PEO. ${ }^{3}$ They suggest that amorphous PLLA is miscible with copolymers. Tsuji et al. reported the stereo-complex formation of PLLA and poly(D-lactide) (PDLA). ${ }^{4-12}$ The melting temperature $T_{\mathrm{m}}$ of the complex increased about $50^{\circ} \mathrm{C}$ in comparison with $T_{\mathrm{m}}$ of pure PLLA.

Younes and Cohn ${ }^{13}$ reported the effects of mixing PEO on the melting and crystallization of PLLA of molecular weight $28000 . T_{\mathrm{m}}$ of PLLA decreased with decreasing weight fraction of PLLA, especially below $W($ PLLA $)=$ 0.2 for some binary mixtures with PEO of molecular weight between 1500 and 35000 .

We reported the effects of mixing PEO on the melting and crystallization of PLLA of molecular weight $2000{ }^{14} T_{\mathrm{m}}$ of PLLA decreased with decreasing weight fraction of PLLA in the binary mixture. It decreased especially below the weight fraction of PLLA 0.2 . Ringed spherulites were observed in optical microscopy for a binary mixture crystallized from the melt, while nonringed spherulites were observed in pure PLLA and PEO crystallized by cooling from the melt.

The miscibility of two polymers has been studied by many authors. However the effects of molecular weight of the higher melting temperature component on the melting and crystallization process have not been reported in the "semi-miscible" crystalline-crystalline polymer mixtures. It is expected that molecular weight effect should appear on the miscibility of the semimiscible crystalline polymer-polymer pairs.

The effects of mixing PEO on the melting and crystallization of PLLA with different molecular weights are studied in this paper. For the purpose of this study,
PLLA of molecular weights 2000, 66000, and 152000 was mixed with PEO of molecular weights 2000,100000 , and 5000000 .

Differential scanning calorimetry (DSC), wide angle X-ray diffraction (WAXD) measurements and optical microscopy were performed for the binary mixture prepared by solution mixing and the sample crystallized from the melt.

\section{EXPERIMENTAL}

The PLLA samples used in this study were purchased from Scientific Polymer Products, Inc. The viscosityaverage molecular weight of PLLA $\left(M_{\eta}\right)$ was determined by measuring the intrinsic viscosity $[\eta]$ in chloroform solution at $30^{\circ} \mathrm{C}$. We used the relationship determined by Schindler and Harper $\left([\eta]=5.45 \times 10^{4} \times M_{\eta}{ }^{0.73}\right)^{15}$ to calculate $M_{\eta} . M_{\eta}$ for the three samples were 2000 (PL2T), 66000 (PL66T), and 152000 (PL152T). PEO samples of molecular weights 100000 (PEO100T) and 5000000 $(\mathrm{PEO} 5 \mathrm{M})$ were purchased from the same company. The PEO sample of molecular weight 3000 (PEO3T) was purchased from Wako Pure Chemical Co. The molecular weight of PEO was used as obtained (catalogue data). The binary mixture was prepared by the same method reported already. ${ }^{14}$ Two polymers were mixed at desired weight fractions and dissolved in chloroform at room temperature and the film sample was obtained by evaporating the solvent at room temperature. The film sample was dried in a vacuum oven for one day at about $40^{\circ} \mathrm{C}$ and used as the original sample.

Rigaku $8230 \mathrm{D}$ with the TAS 200 control system was used for DSC measurement. The as cast film was packed in an aluminum pan and measured in DSC. The heating rate was $6 \mathrm{~K} \mathrm{~min}^{-1}$ and cooling rate, $5 \mathrm{~K} \mathrm{~min}^{-1}$.

Optical microscopic observation was performed by a Nicon polarized light microscope under crossed polars. Film sample formed on a cut slide glass $(3 \mathrm{~mm} \times 3 \mathrm{~mm})$ by evaporating the solvent from solution was used. Film thickness was about $7 \mu \mathrm{m}$ calculated from the weight and area in the laboratory dish using 1.23 as a density 
of amorphous PLLA. ${ }^{16}$ To observe morphological change of the film sample with temperature, a heating device made in our laboratory was used. ${ }^{14}$ The heating rate was almost the same as that of DSC.

WAXD patterns of a sample in the heating and cooling processes were obtained up to $200^{\circ} \mathrm{C}$. A Rod-like sample of $1.8 \mathrm{~mm}$ in diameter was wrapped in aluminum foil and set in the device on the goniometer. $\mathrm{Cu}-K_{\alpha}$ radiation was used as the incident $\mathrm{X}$-ray beam. The heating rate in the WAXD measurements was slightly lower than that of DSC.

\section{RESULTS AND DISCUSSION}

Figure 1 shows the DSC melting curve for the sample prepared by casting from solution of pure PL2T, PL66T, and PL152T. In the heating process, a small endothermic peak due to the glass transition was observed at about $60^{\circ} \mathrm{C}$ for the three samples. An exothermic peak due to the crystallization appeared at about $90^{\circ} \mathrm{C}$. This indicates that crystallization did not occur in solvent casting. Peak melting temperature of the crystal formed in the heating process is about $168^{\circ} \mathrm{C}$ in PL2T and about $175^{\circ} \mathrm{C}$ in PL66T and PL152T. The shoulder that appeared at low temperature of the melting peak in PL2T may be due to the melting of crystallites smaller than crystallites related to the high temperature melting peak. An exothermic peak is observed at low temperature of the melting peak of PL66T. It is considered that delayed crystallization occurred in the heating on amorphous PLLA. Delayed crystallization is observed sometimes in PLLA cast from solution. The molecular motion of PLLA should be strongly restrained by the other molecules during evaporation of the solvent. Therefore, the crystallization in some regions of the sample may be delayed in heating. The DSC melting curves of solution cast film in pure PLLA were very close to those of samples quenched from the melt. ${ }^{1}$

Figure 2 shows the DSC melting curves of pure PL2T, PL66T, and PL152T crystallized from the melt. Crystallization peak is not observed around $90^{\circ} \mathrm{C}$ in the heating process for the three samples cooled from the melt, indicating that PLLA crystallized in the cooling process. The exothermic peak of crystallization was observed at about $110^{\circ} \mathrm{C}$ in DSC curve in the cooling process from

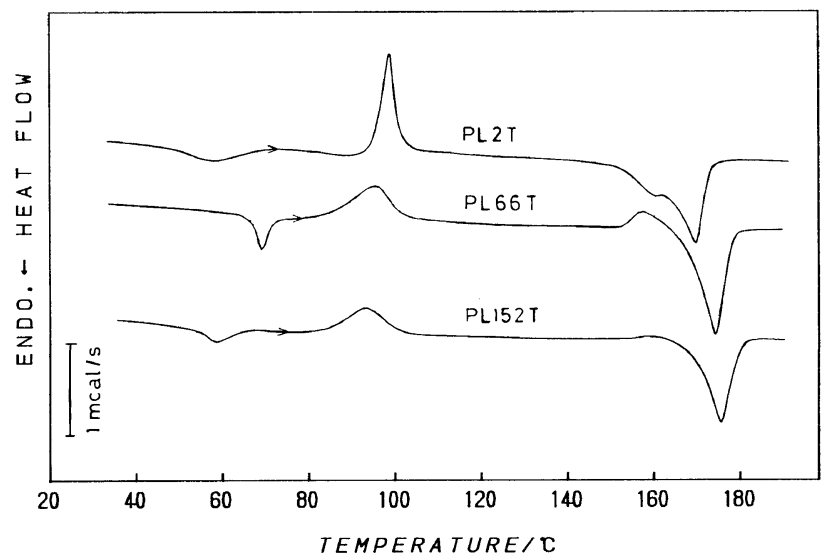

Figure 1. DSC melting curve of three solution cast PLLA samples with different molecular weights. the melt. A double melting peak appears at around $160^{\circ} \mathrm{C}$ in PL2T and around $170^{\circ} \mathrm{C}$ in PL66T, about the same melting temperature region as that of the solution cast samples. There was no change in WAXD patterns at the corresponding temperature, so that phase transition did not occur. The lower temperature peak may be due to the melting of less thickness crystals than crystals corresponding to the high temperature peak. The peak temperature at the higher melting peak is plotted in Figure 6.

Figure 3 shows the DSC melting curve of the binary mixture of PL152T and PEO3T crystallized from the melt for different weight fractions ( $W($ PLLA $))$. The intensity of the melting peak of PLLA decreased with decreasing $W($ PLLA). A small shoulder was observed below the endothermic peak of melting in $W(\mathrm{PL} 152 \mathrm{~T})=$ 0.8 . This shoulder may be due to the melting of less thickness crystals of PL152T than crystals corresponding to the high temperature peak, because no change indicating phase transition was observed in the WAXD patterns. The melting peak shifted to the low temperature side slightly in $W(\mathrm{PLLA})=0.4$. The melting peak of PEO is not observed at $W(\mathrm{PLLA})=0.8$. This indicates that the crystallization of PEO did not occur in this sample. In the cooling process from the melt of the binary mixture, a crystallization peak was observed at

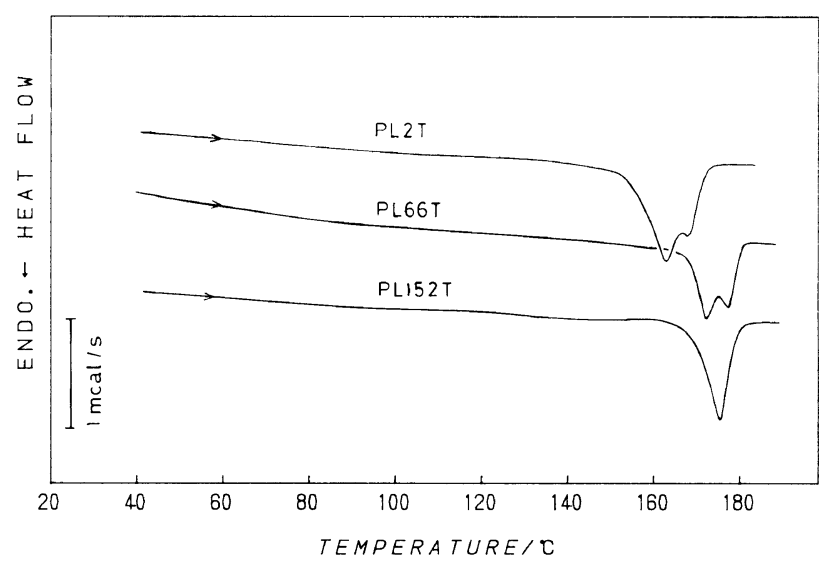

Figure 2. DSC melting curve of three PLLA samples crystallized from the melt.

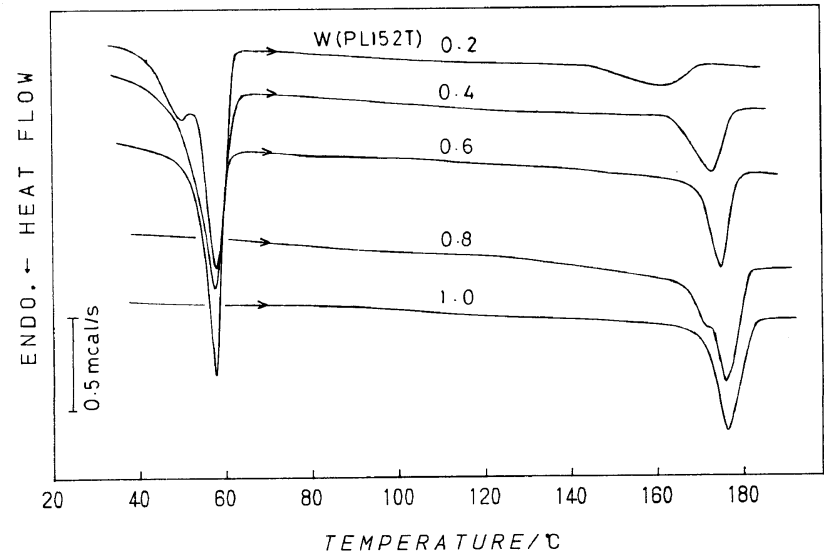

Figure 3. DSC melting curve of the binary mixture of PL152T/ PEO3T crystallized from the melt of different weight fractions of PLLA. 


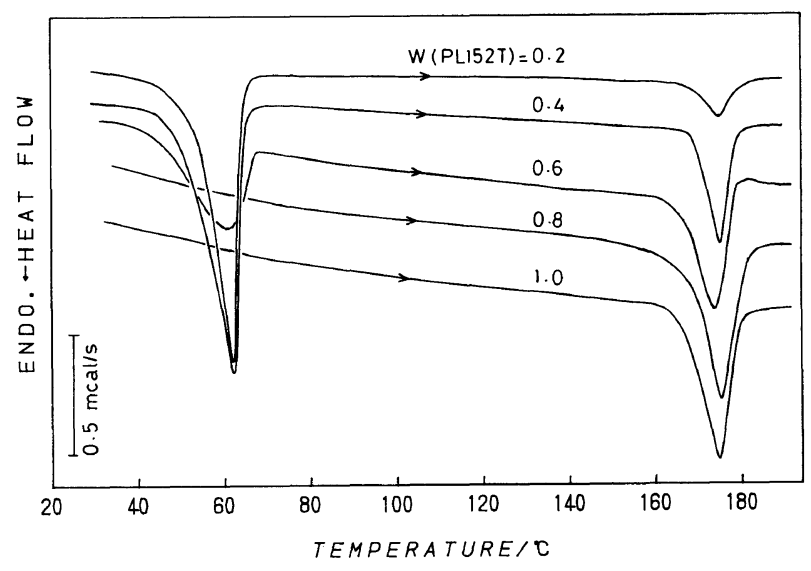

Figure 4. DSC melting curve of the binary mixture of PL152T/ PEO5M crystallized from the melt with different weight fractions.

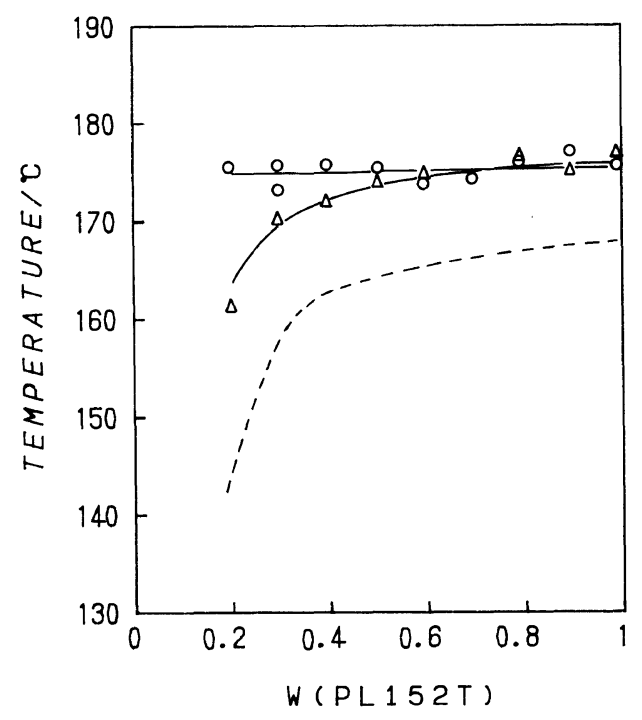

Figure 5. $T_{\mathrm{m}}$ of PL152T with $W(\mathrm{PL} 152 \mathrm{~T})$ in the mixture with PEO3T and PEO5M. $\triangle$, PL152T/PEO3T; O, PL152T/PEO5M. Dotted curve shows $T_{\mathrm{m}}$ of PL2T in the mixture with PEO3T. ${ }^{14}$

about $110^{\circ} \mathrm{C}$. Crystallization of PEO should be hindered by PLLA crystals because the crystallization temperature $\left(T_{\mathrm{c}}\right)$ of PEO is much lower than $T_{\mathrm{c}}$ of PLLA (about $40^{\circ} \mathrm{C}$ ). The PLLA amorphous phase may accommodate some PEO molecules as indicated by Younes and Cohn. ${ }^{13}$

Figure 4 shows the DSC melting curves of a binary mixture of PL152T and PEO5M with different weight fractions crystallized from the melt. The intensity of the melting peak of PLLA decreased with decreasing weight fraction of PLLA. The melting peak of PEO appeared clearly below $W($ PLLA $)=0.6$. This indicates that the crystallization of PEO is also hindered in this mixture during cooling by PLLA crystallized at higher temperature in the mixture at a weight fraction above 0.8 .

Figure 5 shows $T_{\mathrm{m}}$ of PL152T with change of the weight fraction in the binary mixture with PEO. In the case of PL2T/PEO3T mixture, ${ }^{14}$ a gradual decrease of $T_{\mathrm{m}}$ was observed from $W($ PLLA $)=1.0$ to 0.3 and it drastically decreased below, 0.2 as shown by the dotted curve. $T_{\mathrm{m}}$ also decreased with decreasing PLLA content. In the binary mixture of PL152T/PEO3T, it drastically

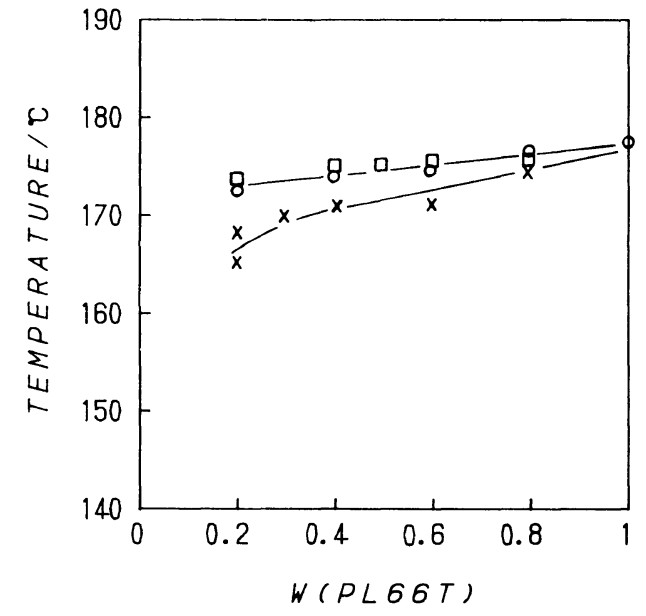

Figure 6. $T_{\mathrm{m}}$ of PL66T with $W(\mathrm{PL} 66 \mathrm{~T})$ in the mixture with PEO3T, PEO10T and PEO5M. O, PL66T/PEO5M; $\square$, PL66T/PEO10T; $\times$, PL66T/PEO3T.

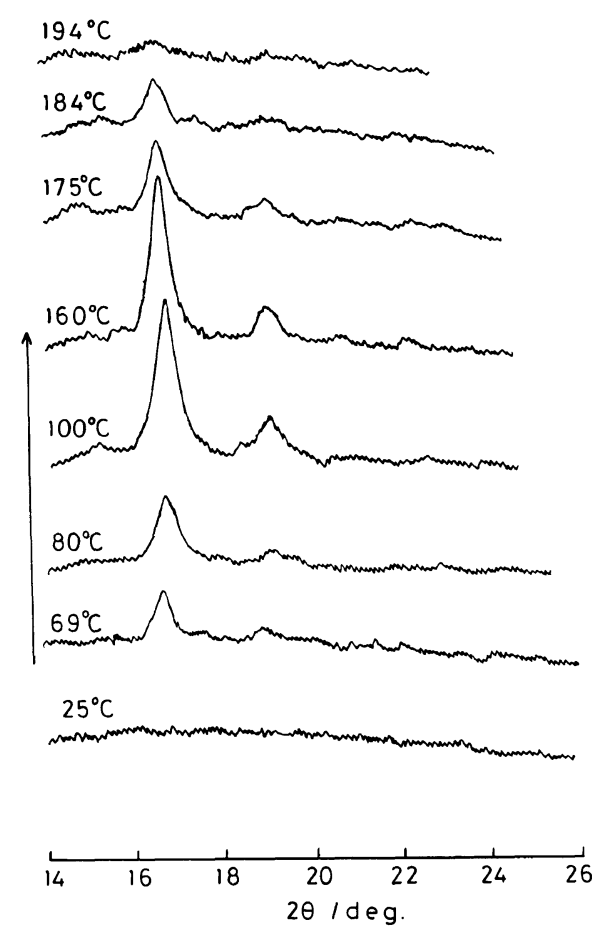

Figure 7. WAXD pattern of pure PL152T sample cast from solution in the heating process (from bottom to top).

decreased below $W($ PLLA $)=0.2 . T_{\mathrm{m}}$ of PL152T did not decrease in the whole range of the weight fraction in the mixture with PEO5M.

Figure 6 shows $T_{\mathrm{m}}$ of PL66T with change of the weight fraction in the binary mixture with PEO. $T_{\mathrm{m}}$ of PL66T in the mixture decreased with decreasing $W$ (PL66T) but the decreasing rate in the mixture with PEO3T was larger than that of the mixture with PEO100T and PEO5M. These features in Figures 5 and 6 indicate that the decreasing rate of $T_{\mathrm{m}}$ of PLLA depends on the molecular weight of PLLA and PEO in the mixture.

Figure 7 shows temperature changes of WAXD patterns of pure PL152T sample cast from solution. The diffraction of the sample at $25^{\circ} \mathrm{C}$ shows no diffraction peaks. In the heating process, diffraction peaks from (110) and (200) of PL152T appear from $69^{\circ} \mathrm{C}$, this being 


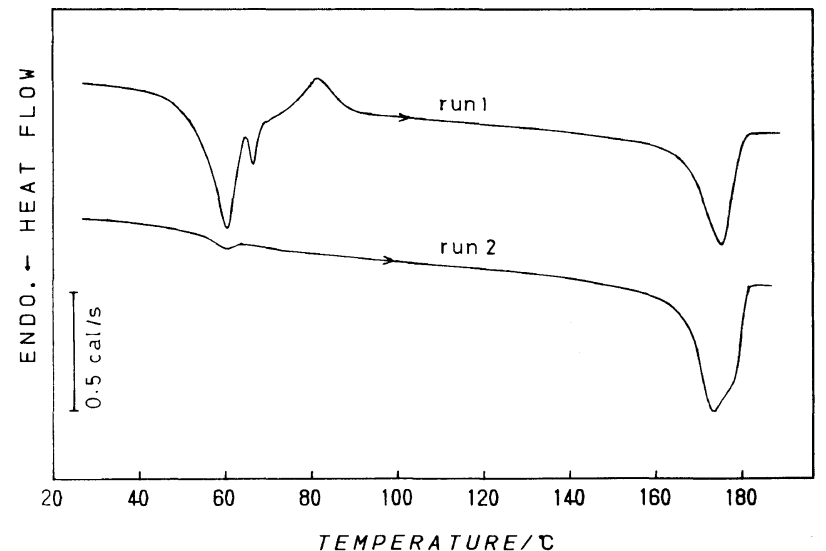

Figure 8. DSC melting curve of PL152T/PEO5M binary mixture (6/4). Run 1, solution cast film; run 2, sample cooled from the melt after run 1 .

just below the temperature of the exothermic peak that appeared in the DSC curve in Figure 1. The crystal structure of PLLA determined by De Santis and Kovacs is pseudo-hexagonal with dimensions of $a=1.07 \mathrm{~nm}$, $b=0.645 \mathrm{~nm}, c=2.78 \mathrm{~nm}$, and $\alpha=\beta=\gamma=90^{\circ} .{ }^{17}$ The (110) diffraction peak appeared at $80^{\circ} \mathrm{C}$ that corresponds to the crystallization temperature in the heating process (Figure 1) but it did not grow completely. The peak intensity was saturated at $100^{\circ} \mathrm{C}$ and it did not change up to $160^{\circ} \mathrm{C}$. The intensity decreased at $175^{\circ} \mathrm{C}$ that corresponds to the melting peak temperature in the DSC curve. The (110) peak still remained at $184^{\circ} \mathrm{C}$ that is above the melting peak in the DSC curve. The peak disappeared completely at $194^{\circ} \mathrm{C}$ above the melting peak in the DSC curve. In the cooling process, the diffraction peak again appeared at $120^{\circ} \mathrm{C}$ slightly above the crystallization peak of PLLA on the DSC curve. The diffraction pattern at $25^{\circ} \mathrm{C}$ crystallized by cooling from the melt is the same as that of crystals grown in the heating process of the sample prepared by casting from solution. The diffraction pattern of PL2T and temperature change in the heating process ${ }^{14}$ were almost the same as for PL152T.

As an example of the melting and crystallization process of the binary mixture in the high molecular weight samples, we discuss the results of DSC and WAXD measurements of PL152T and PEO5M mixture of $W(\mathrm{PLLA})=0.6$. Figure 8 shows the DSC melting curve of the solution cast sample (run 1) and sample crystallized from the melt (run 2) of a PL152T/PEO5M binary mixture. The endothermic melting peak of PEO appeared at about $60^{\circ} \mathrm{C}$. A small endothermic peak is observed above the PEO melting peak but the reason is not clear now. An exothermic peak of crystallization of PLLA appeared in run 1. An endothermic peak of melting of PLLA was observed at about $175^{\circ} \mathrm{C}$, and was composed of two peaks. This may be due to the melting of crystals with different thickness grown during cooling. Taking into account WAXD below the melting, melt recrystallization of PLLA need not be considered. $T_{\mathrm{m}}$ of PLLA did not change with the weight fraction in the solution cast sample.

Figure 9 shows the temperature change of the WAXD pattern of the binary mixture (PL152T/PEO5M) of

Polym. J., Vol. 28, No. 7, 1996

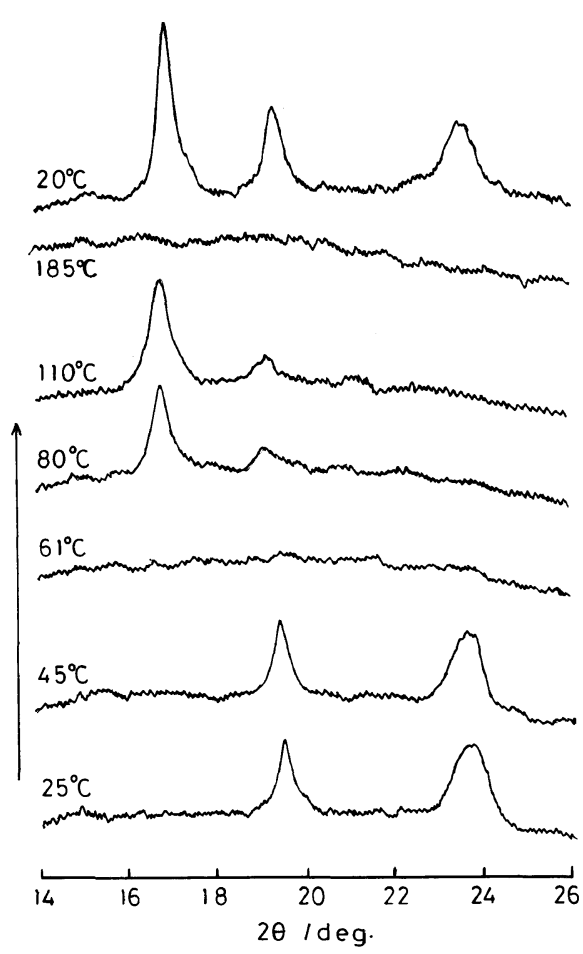

Figure 9. WAXD pattern of PL152T/PEO5M mixture of $W($ PLLA $)=$ 0.6 cast from solution in the heating process.

$W(\mathrm{PL} 152 \mathrm{~T})=0.6$. Diffraction peaks from (120) and (112) of PEO monoclinic crystals are observed in the sample cast from solution. The diffraction peak from PLLA is not observed at this temperature. The diffraction peak from PEO still appears at $45^{\circ} \mathrm{C}$ in the heating process but the peak disappeared at $61{ }^{\circ} \mathrm{C}$ that corresponds to the melting peak of PEO (Figure 8). On further heating, the peak from PLLA appears at $80^{\circ} \mathrm{C}$ and intensity increases with temperature. At $185^{\circ} \mathrm{C}$ above the melting peak in the DSC curve, no diffraction peak from PLLA was observed. The binary mixture cooled from the melt shows the diffraction peaks from PLLA and PEO crystal as shown in the top diffraction pattern. The temperature change of the WAXD pattern from pure PL152T and binary mixture of PL152T/PEO5M supports the melting behavior as shown by the DSC curve in heating of the solution cast sample except for slight difference in temperature during melting.

Figure 10 shows the morphological change of pure PL152T cast from solution with temperature. No crystals were observed in the solution cast sample of pure PL152T (a). No change was seen in the temperature range from $25^{\circ} \mathrm{C}$ to $90^{\circ} \mathrm{C}$. Small crystals appear from about $90^{\circ} \mathrm{C}$ and the area under the microscope was covered by many small crystals at $100^{\circ} \mathrm{C}$ (b). These crystals were observed up to $180^{\circ} \mathrm{C}$ and then the crystals disappeared above $190^{\circ} \mathrm{C}$ as shown in (c). In the cooling process, small crystals appeared from $162^{\circ} \mathrm{C}$ and grew with decreasing temperature to $25^{\circ} \mathrm{C}(\mathrm{d})$. Spherulite was not formed in the film cast from solution and sample cooled from the melt, though large spherulite was formed in pure PL2T cooled from the melt as shown in Figure 11. In our experiment, the cooling rate was about $6 \mathrm{~K} \mathrm{~min}^{-1}$ for all samples. Tsuji and Ikada reported that large spherulites are formed by annealing at a temperature of $140^{\circ} \mathrm{C}$ for $600 \mathrm{~min}$ on the PLLA sample 

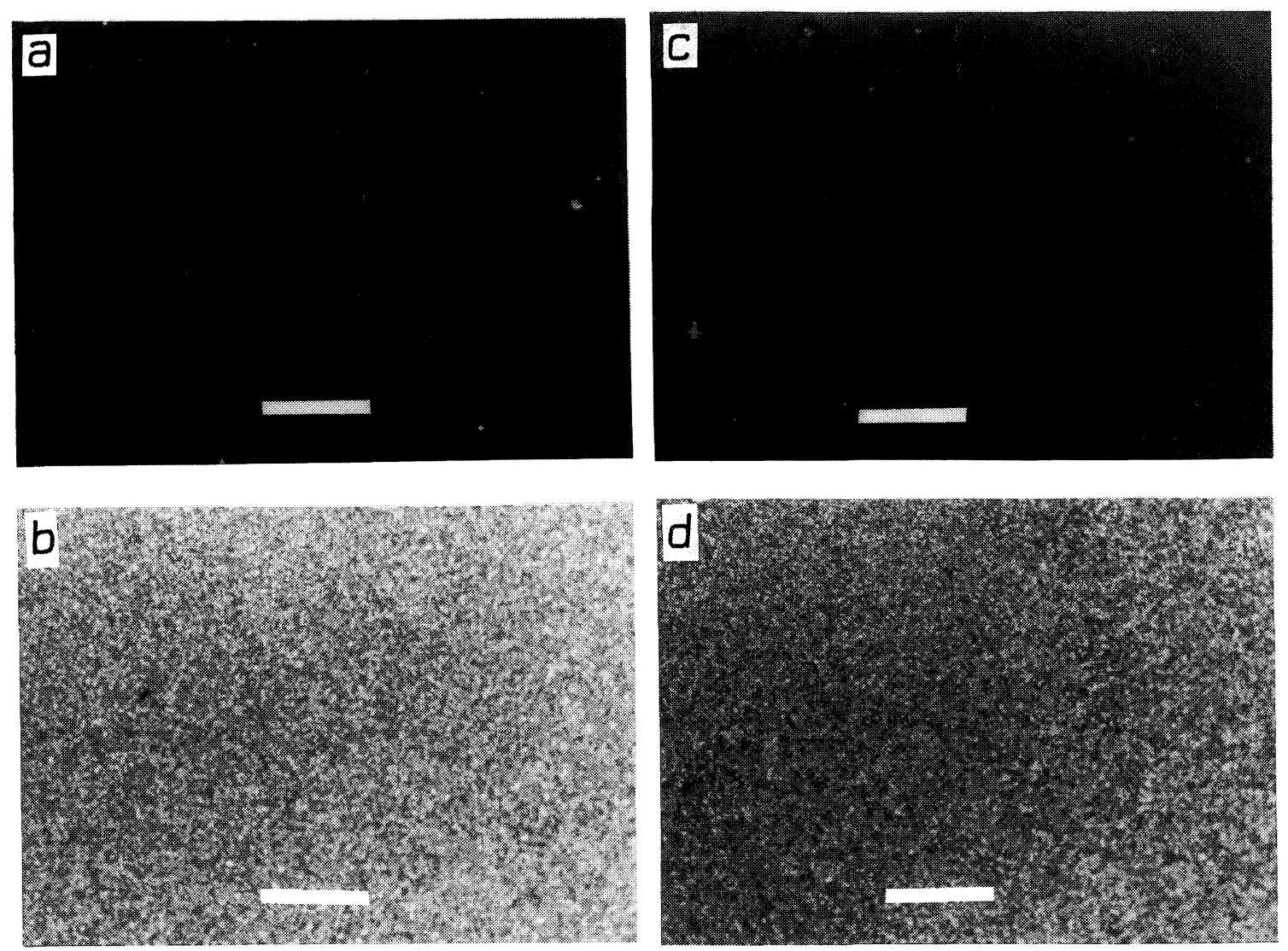

Figure 10. Morphological change under polarized light microscope (crossed polars) of pure PL152T cast from solution in the heating process ((a), (b), (c)) and cooled from the melt (d). Scale bar $=1 \mu \mathrm{m}$. (a) $25^{\circ} \mathrm{C}$; (b) $110^{\circ} \mathrm{C}$; (c) $202^{\circ} \mathrm{C}$; (d) $25^{\circ} \mathrm{C}$.

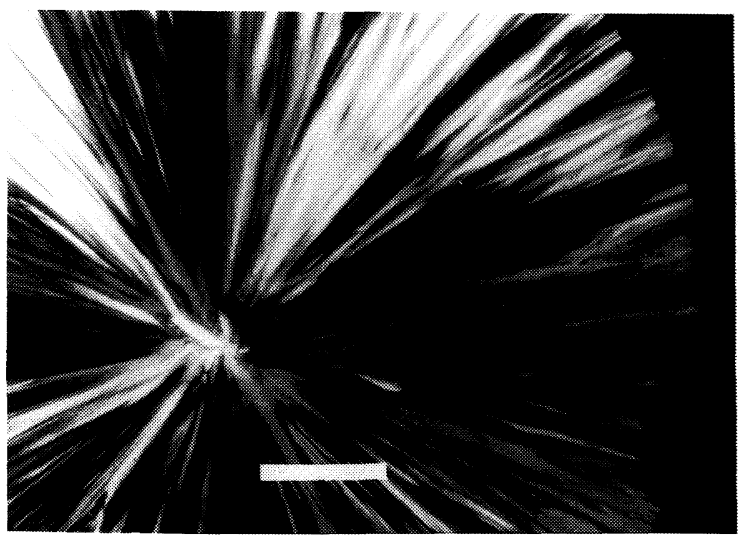

Figure 11. Optical micrograph (crossed polars) of pure PL2T crystallized from the melt.

of $M W=300000,{ }^{18}$ so that the morphology of the high molecular weight PLLA should depend on crystallization conditions.

Figure 12 shows the temperature change of the optical micrograph of the binary mixture (PL152T/PEO5M) of $W(\mathrm{PL} 152 \mathrm{~T})=0.6$ cast from solution. Small crystals are observed in the dark area at $25^{\circ} \mathrm{C}$ (a). In the heating process, small crystals disappear at about $65^{\circ} \mathrm{C}(\mathrm{b})$ that corresponds to the melting temperature of PEO5M in the mixture, therefore the small crystals observed in the sample cast from solution are those of PEO. On further heating, small crystals appear again at $98^{\circ} \mathrm{C}$ (c), and these crystals disappear at about $175^{\circ} \mathrm{C}$ that is close to the peak melting temperature of PLLA in the DSC curve. Small spherulites grew at about $125^{\circ} \mathrm{C}$ in the cooling process in the whole area under the microscope and the area became brighter at $40^{\circ} \mathrm{C}$ (d) that corresponds to the crystallization peak temperature of $\mathrm{PEO}$ in the DSC curve. In the 2nd heating, the spherulite became dark above $65^{\circ} \mathrm{C}$ indicating the melting of PEO lamellae. The spherulite should be composed of PEO and PLLA lamellae as already discussed in the case of PL2T and PEO3T. ${ }^{14}$ Crystallization of pure PL152T molecule from the melt should be impeded by the other PLLA molecules. However, PEO molecules in the liquid state should act as a lubricant in the crystallization of PLLA in the binary mixture. Therefore, the spherulite of PLLA is formed during cooling. In the case of PL2T/ PE03T, molecules of PLLA and PEO are not so long, so that the impeding effect of PEO on the crystallization of PLLA is not large and a ringed spherulite should be formed.

Figure 13 shows the morphological change of pure PL66T with temperature. No crystals are observed in this sample cast from solution (a). Small crystals appear at $90^{\circ} \mathrm{C}$ (b) in the heating process, and this continues to $175^{\circ} \mathrm{C}$. These small crystals disappear above this temperature (c). Small crystals and spherulites are formed (d) in the cooling process. It is considered from the observation of spherulites that the mobility of PL66T molecules in the melt is larger than that of pure PL152T, so that spherulites are formed in pure PL66T.

Figure 14 shows morphological change of the PL66T/ 

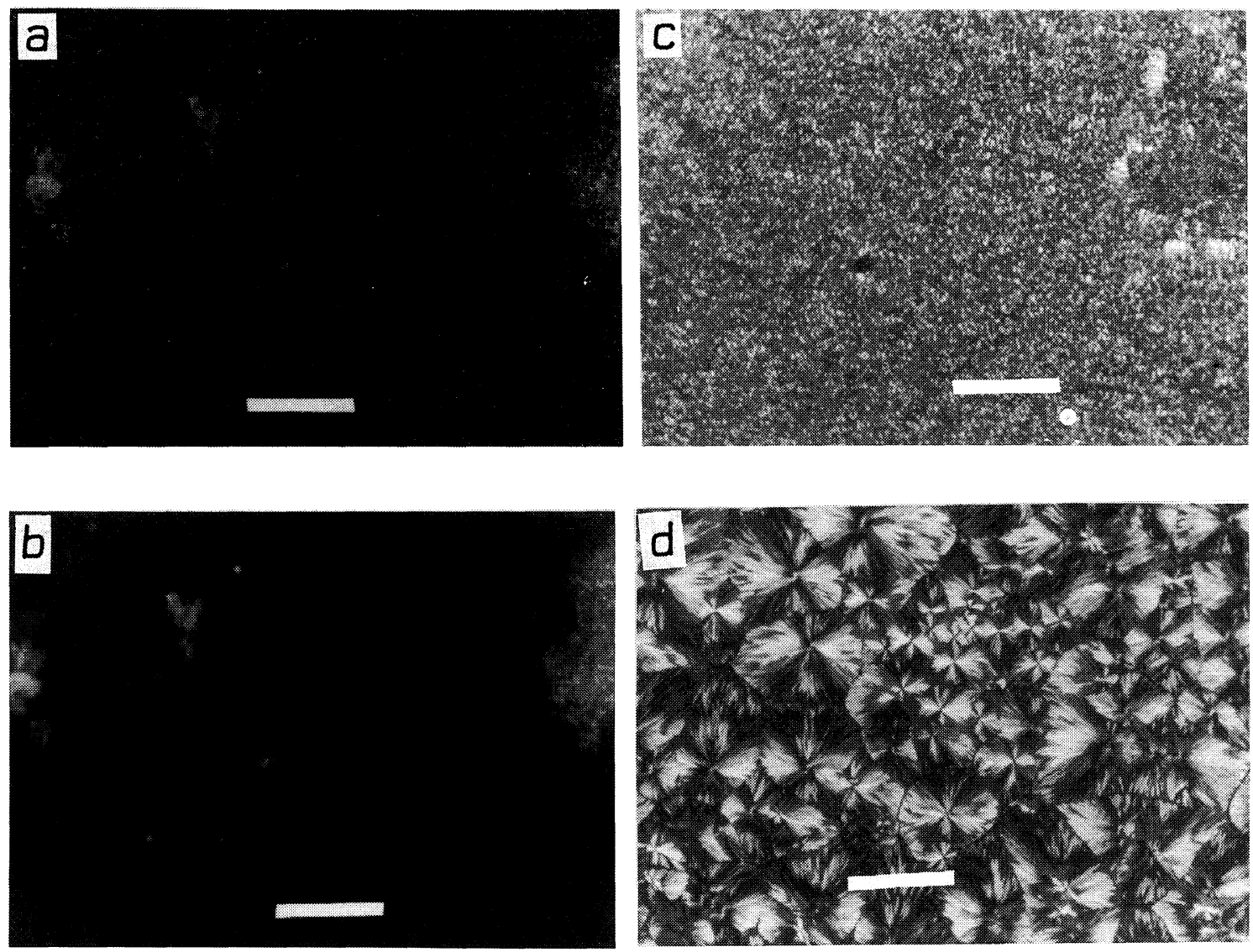

Figure 12. Temperature change of the morphology under microscope (crossed polars) of PL152T/PEO5M mixture of $W(\mathrm{PL} 152 \mathrm{~T})=0.6$ cast from solution in the heating process ((a), (b), (c)) and cooled from the melt (d). (a) $25^{\circ} \mathrm{C}$; (b) $65^{\circ} \mathrm{C}$; (c) $98^{\circ} \mathrm{C}$; (d) $40^{\circ} \mathrm{C}$.
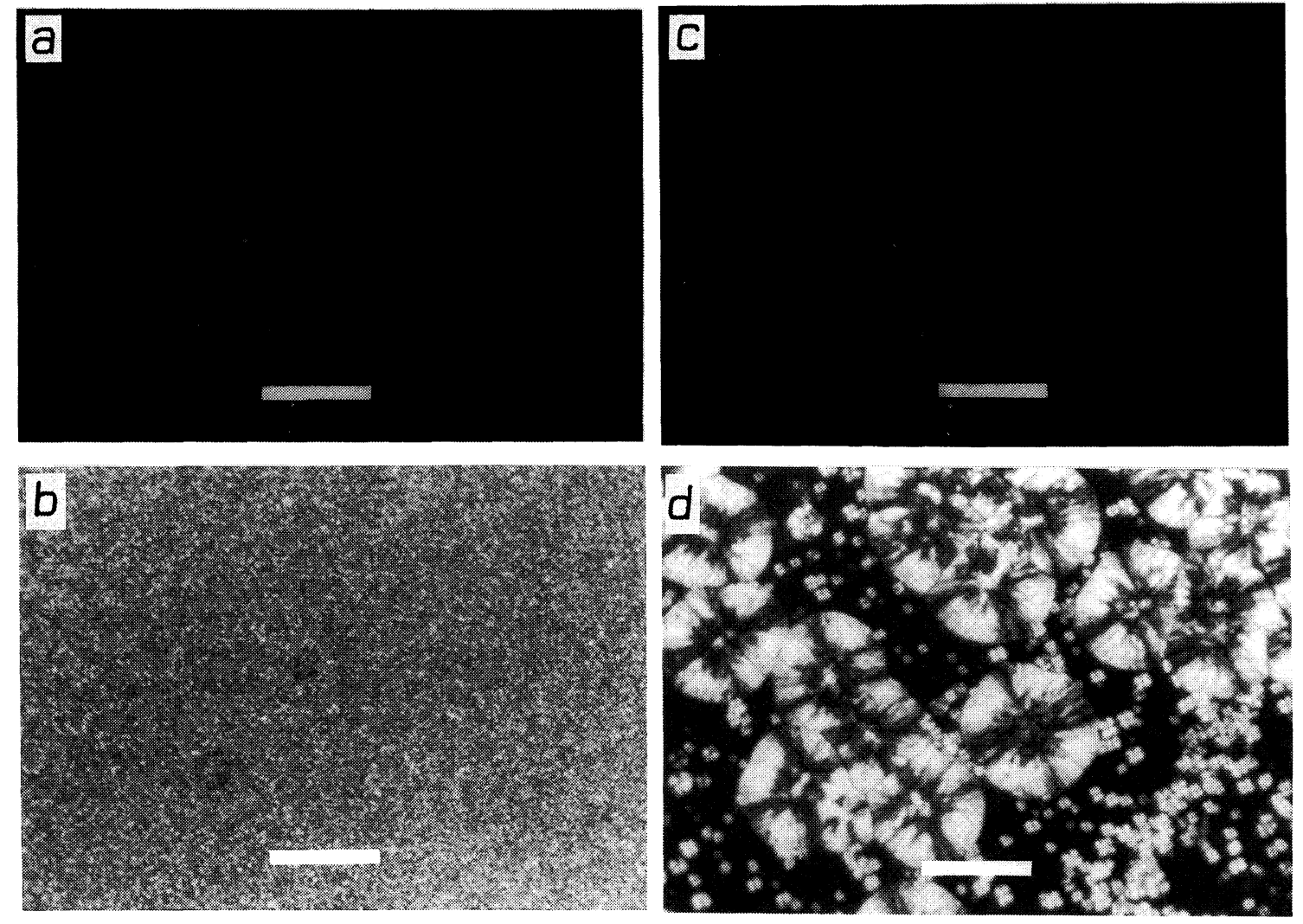

Figure 13. Temperature change of morphology under the polarized microscope of pure PL66T cast from solution in the heating process ((a), (b), (c)) and cooled from the melt (d). (a) $25^{\circ} \mathrm{C}$; (b) $96^{\circ} \mathrm{C}$; (c) $175^{\circ} \mathrm{C}$; (d) $25^{\circ} \mathrm{C}$ 

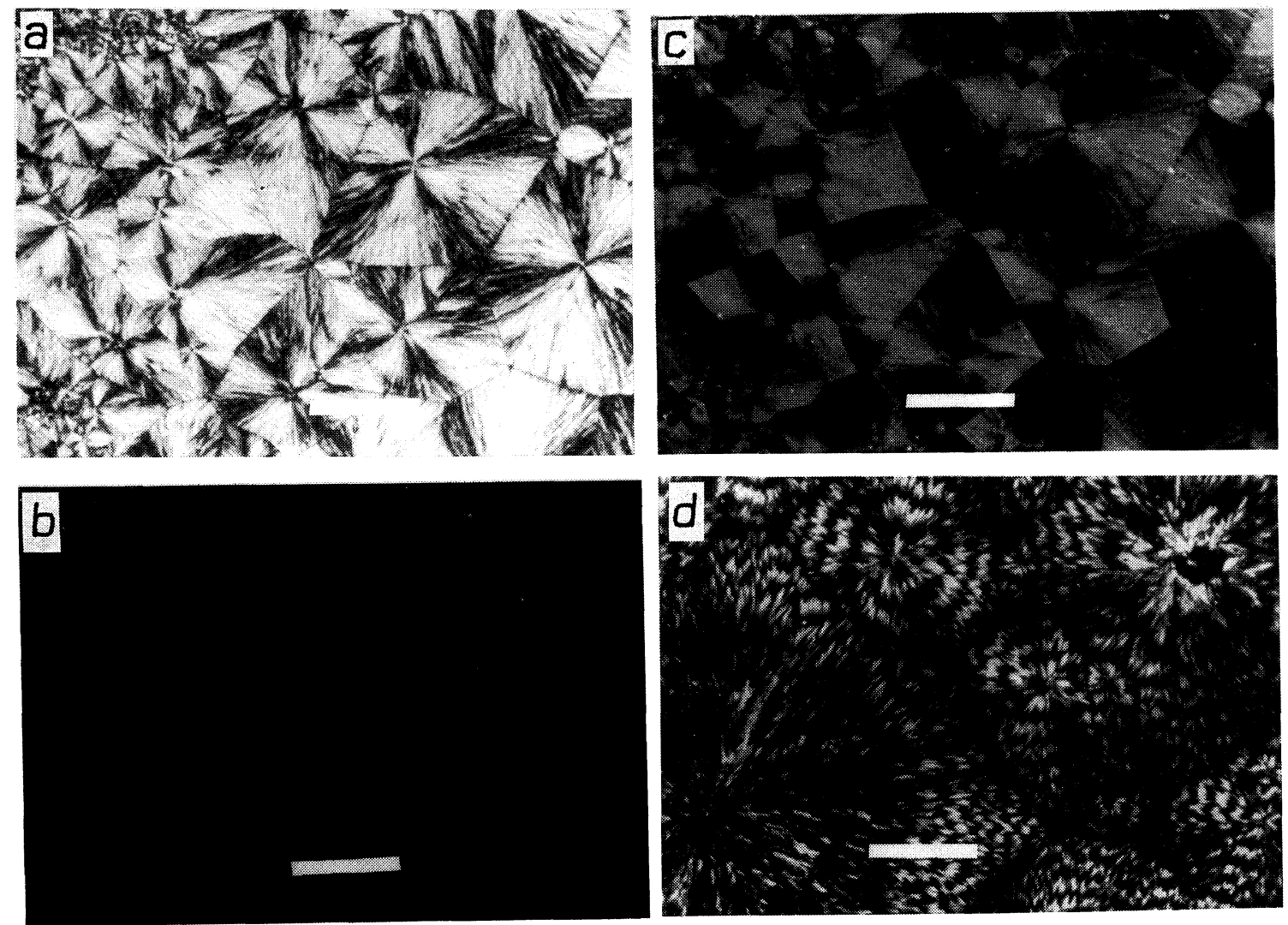

Figure 14. Temperature change of the morphology of the PL66T/PEO5M mixture of $W(\mathrm{PL66T})=0.6$ cast from solution in the heating process ((a), (b), (c)) and cooled from the melt (d). (a) $25^{\circ} \mathrm{C}$; (b) $62^{\circ} \mathrm{C}$; (c) $98^{\circ} \mathrm{C}$; (d) $25^{\circ} \mathrm{C}$.

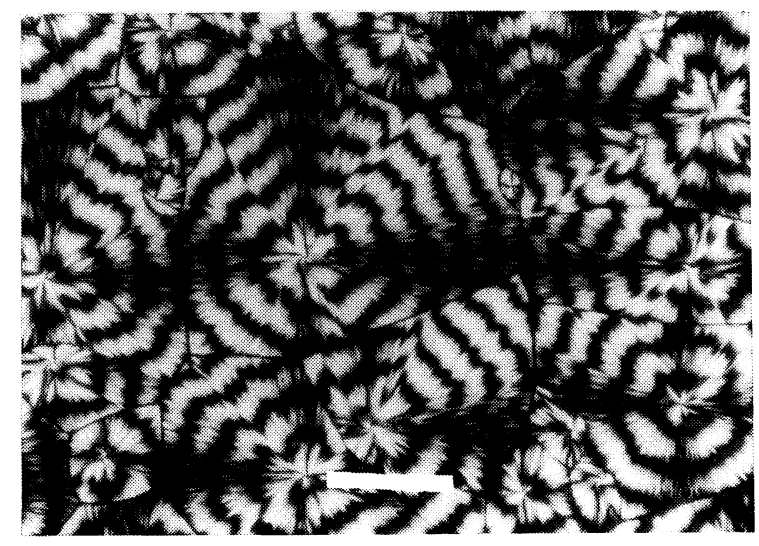

Figure 15. Optical micrograph at $25^{\circ} \mathrm{C}$ of the PL2T/PEO3T binary mixture cooled from the melt.

PEO5M binary mixture of $W(\mathrm{PL66T})=0.6$ with temperature. The temperature change of these photographs corresponds to the DSC curve of PL66T as shown in Figures 1 and 2. Spherulites are observed at room temperature in the solution cast sample (a). These spherulites disappeared at about $65^{\circ} \mathrm{C}$ that corresponds to the melting peak in heating in the DSC curve (b). Spherulites of PLLA appear at about $90^{\circ} \mathrm{C}$ as shown in (c). In the cooling process from the melt, spherulites are formed at about $110^{\circ} \mathrm{C}$. As already reported, ringed spherulites are formed in the PL2T and PEO3T binary mixture cooled from the melt as observed in Figure 14. The spherulite is composed of PLLA and PEO lamellae. ${ }^{14}$ In the mixture of PLLA with molecular weight
66000 and PEO, PEO should again act as a lubricant and a ringed spherulite is formed during cooling from the melt, though a non-ringed spherulite is formed in the pure PL66T.

In conclusion, increased viscosity (or decreased molecular mobility) of molten high molecular weight PLLA resulted in decreased crystallizability, so that small crystallites are formed in the cooling process from the melt. Mixing PEO should increase the mobility of long molecules of PLLA in the melt and spherulites are formed in the binary mixture. Crystallization did not occur in cooling from the melt of the pure PLLA under high pressure, while in the binary mixture with PEO, spherulites were formed. ${ }^{19}$ This indicates the diluent effect of PEO in the crystallization of PLLA. In low molecular weight PLLA, large spherulites were formed during cooling from the melt even in the sample without PEO. The high molecular weight PLLA did not crystallize in the mixture with or without PEO in the sample prepared by casting from solution.

$T_{\mathrm{m}}$ of PLLA decreased with increasing PEO content in the mixture, when the molecular weight of PEO is low. If the ultra-high molecular weight PEO is mixed, $T_{\mathrm{m}}$ of PL152T does not decrease. This indicates that the solvent effect of PEO decreases with molecular weight.

\section{REFERENCES}

1. B. Kalb and A. J. Pennings, Polymer, 21, 607 (1980).

2. C. Migliaresi, D. Cohn, A. De Lollis, and L. Fambri, J. Appl. Polym. Sci., 43, 83 (1991). 
3. T. G. Park, S. Cohen, and R. Langer, Macromolecules, 25, 116 (1992).

4. Y. Ikada, K. Jamshidi, H. Tsuji, and S.-H. Hyon, Macromolecules, 20, 904 (1987).

5. H. Tsuji, F. Horii, S.-H. Hyon, and Y. Ikada, Macromolecules, 24, 2719 (1991).

6. H. Tsuji, S.-H. Hyon, and Y. Ikada, Macromolecules, 24, 5651 (1991).

7. H. Tsuji, S.-H. Hyon, and Y. Ikada, Macromolecules, 24, 5657 (1991).

8. H. Tsuji, S.-H. Hyon, and Y. Ikada, Macromolecules, 25, 2940 (1992).

9. H. Tsuji and Y. Ikada, Macromolecules, 25, 5719 (1992).
10. H. Tsuji, F. Horii, M. Nakagawa, Y. Ikada, H. Odani, and R. Kitamaru, Macromolecules, 25, 4114 (1992).

11. H. Tsuji, Y. Ikada, S.-H. Hyon, Y. Kimura, and T. Kitano, $J$. Appl. Polym. Sci., 51, 337 (1994).

12. H. Tsuji and Y. Ikada, Macromolecules, 26, 6918 (1993).

13. H. Younes and D. Cohn, Eur. Polym. J., 24, 765 (1988).

14. C. Nakafuku and M. Sakoda, Polym. J., 25, 909 (1993).

15. A. Schindler and D. Harper, J. Polym. Sci., Polym. Chem. Ed., 17, 2593 (1979).

16. C. Nakafuku, unpublished data.

17. P. De Santis and A. J. Kovacs, Biopolymers, 6, 299 (1968).

18. H. Tsuji and Y. Ikada, Polymer, 36, 2709 (1995).

19. C. Nakafuku, Polym. J., 26, 680 (1994). 